\title{
Distinct Midbrain and Habenula Pathways Are Involved in Processing Aversive Events in Humans
}

\author{
DEelly Hennigan, ${ }^{1}$ Kimberlee D’Ardenne, ${ }^{2}$ and Samuel M. McClure ${ }^{1}$ \\ ${ }^{1}$ Department of Psychology, Stanford University, Stanford, California 94305, and ${ }^{2}$ Virginia Tech Carilion Research Institute, Roanoke, Virginia 24016
}

Emerging evidence implicates the midbrain dopamine system and its interactions with the lateral habenula in processing aversive information and learning to avoid negative outcomes. We examined neural responses to unexpected, aversive events using methods specialized for imaging the midbrain and habenula in humans. Robust activation to aversive relative to neutral events was observed in the habenula and two regions within the ventral midbrain: one located within the ventral tegmental area (VTA) and the other in the substantia nigra (SN). Aversive processing increased functional connectivity between the VTA and the habenula, putamen, and medial prefrontal cortex, whereas the SN exhibited a different pattern of functional connectivity. Our findings provide evidence for a network comprising the VTA and SN, the habenula, and mesocorticolimbic structures that supports processing aversive events in humans.

Key words: aversion; avoidance; dopamine; fMRI; midbrain; ventral tegmental area

\section{Introduction}

Seeking rewards and avoiding punishments are fundamental behaviors for all species. The mesencephalic dopamine (DA) system plays an important role in these motivational behaviors, most notably by encoding reward prediction errors (Schultz et al., 1997) that underlie positive arousal and reward learning.

Although DA function is well understood in the context of rewards, the role of DA in encoding aversive stimuli remains less clear. Conventionally, midbrain DA neurons are viewed as a homogeneous functional group that transmits reward prediction errors across the forebrain. However, animal studies have identified DA subpopulations that are excited by aversive events (including electric shocks, tail pinches, air puffs, and cues predicting these stimuli), which is explicitly at odds with reward prediction error encoding (Mantz et al., 1989; Guarraci and Kapp, 1999; Brischoux et al., 2009; Matsumoto and Hikosaka, 2009b). Exposure to aversive or stressful stimuli increases extracellular DA concentration in selective target regions (Thierry et al., 1976; Abercrombie et al., 1989), which further suggests that responses to aversive events differ across DA subpopulations.

Connectivity with the lateral habenula may determine responses of the DA cells to aversive events. Lateral habenula neurons are excited by aversive stimuli and associated predictive cues and are inhibited by rewarding cues and outcomes (Matsumoto and Hikosaka, 2009a). Whereas some habenula neurons indi-

\footnotetext{
Received March 7, 2014; revised Nov. 4, 2014; accepted Nov. 6, 2014.

Author contributions: K.H. and S.M.M. designed research; K.H. performed research; K.D. and S.M.M. contributed unpublished reagents/analytic tools; K.H. analyzed data; K.H., K.D., and S.M.M. wrote the paper.

This work was supported by a grant from the Stanford Institute for Neuro-Innovation and Translational Neuroscience and National Institute on Drug Abuse Grant R03 032580 (S.M.M.). We thank Keifer Katovich for assistance in data collection.

The authors declare no competing financial interests.

Correspondence should be addressed to Kelly Hennigan, 450 Serra Mall, Building 420, Stanford, CA 94305. E-mail: hennigan@stanford.edu.

DOI:10.1523/JNEUROSCI.0927-14.2015

Copyright $\odot 2015$ the authors $\quad 0270-6474 / 15 / 350198-11 \$ 15.00 / 0$
}

rectly inhibit reward-predicting DA cells (Christoph et al., 1986; Ji and Shepard, 2007; Matsumoto and Hikosaka, 2007; Jhou et al., 2009; Hong et al., 2011; Stamatakis and Stuber, 2012), other habenula projections directly excite DA neurons within the rodent ventral tegmental area (VTA; Lammel et al., 2012). Optogenetic activation of this direct habenula-VTA pathway induces conditioned place avoidance, demonstrating the important role DA activation plays in aversive processing (Lammel et al., 2012). Other rodent work corroborates the role of DA in conditioned place avoidance by showing that phasic DA excitation is necessary for fear conditioning (Pezze and Feldon, 2004; Fadok et al., 2009; Zweifel et al., 2009, 2011).

It remains unknown whether functional differences exist within the primate DA system with respect to reward and aversive processing. Monkey cell recordings suggest that a subclass of aversive-excited DA neurons exist and are functionally distinct from reward-predicting DA cells, which are either unresponsive or inhibited by aversive stimuli (Matsumoto and Hikosaka, 2009b; Bromberg-Martin et al., 2010). Other work argues that the midbrain DA system is a functionally homogenous population that only truly encodes reward prediction errors in a parametric manner (Fiorillo, 2013; Fiorillo et al., 2013).

In the present study, we investigate the role of the DAergic midbrain [i.e., substantia nigra (SN) and VTA] and habenula in processing aversive events in humans. We measured functional activity from these regions as participants experienced rewarding, aversive, and neutral stimuli. We tested whether subregions of DAergic midbrain were differentially responsive to aversive events and whether they were functionally connected with the habenula during aversive processing. We also examined functional connectivity between the SN, VTA, and forebrain target structures to identify DA-related circuits involved in processing aversive stimuli. 
A

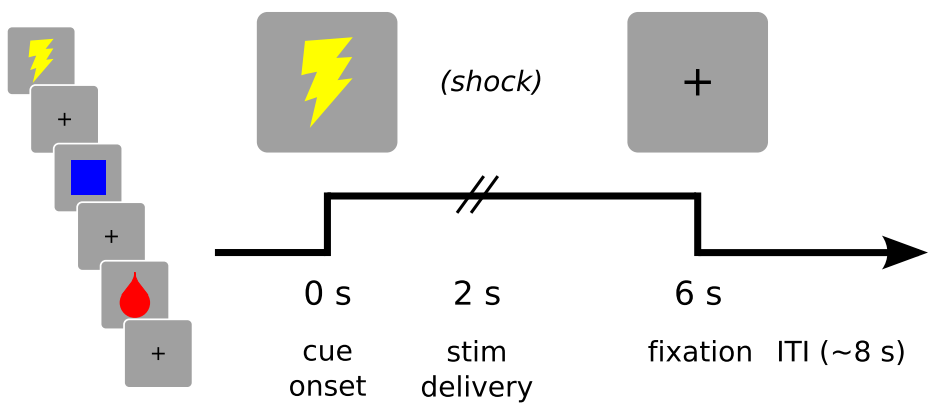

B

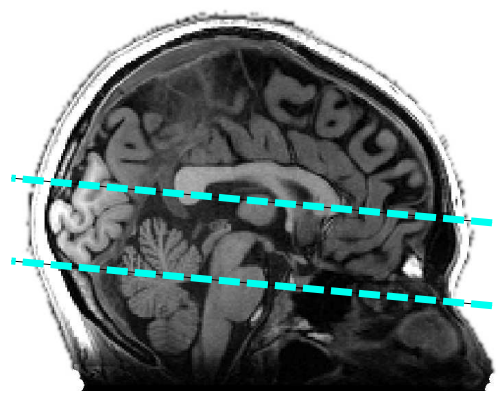

Figure 1. A, Experiment paradigm. Participants experienced three types of events: shock, neutral, and juice trials. Each event was composed of a 6-s-duration visual cue and delivery of a reinforcer 2 s after cue onset, except for neutral trials, for which there was no reinforcer. The visual cues associated with shock, neutral, and juice events are shown on the left, respectively. The figure to the right depicts the progression of a shock trial. $\boldsymbol{B}$, Acquired data covered a partial volume oblique slab that included the midbrain, habenula, and ventral aspects of the striatum and frontal cortex for each participant.

\section{Materials and Methods}

Participants. A total of 19 healthy adults participated in the study. Participants were excluded if they reported any history of psychiatric illness or current use of psychotropic medication or if they were deemed ineligible for magnetic resonance scanning (e.g., metal implants, claustrophobia, pregnancy). None of the participants were obese (the body mass index of all participants was $<30$ ). One participant was excluded because the acquisition volume only partially covered the habenulae, leaving 18 participants in the final dataset (mean age, $28.1 \pm 11.5$ years; eight females). All participants gave informed written consent using protocol approved by the Stanford Institutional Review Board and were paid for their participation.

Data acquisition. The small size and location of midbrain nuclei and the habenula make them challenging to study in humans using noninvasive techniques such as functional magnetic resonance imaging (fMRI). This challenge is attributable in part to the size of the structures. The SN and VTA have a combined volume of $\sim 900 \mathrm{~mm}^{3}$ (Eapen et al., 2011), and the volume of the habenula (medial and lateral inclusively) is $\sim 30 \mathrm{~mm}^{3}$ in each hemisphere, or approximately the size of one voxel using standard functional acquisition protocols (Ranft et al., 2010; Lawson et al., 2013). Mesencephalic and diencephalic structures are also particularly susceptible to motion artifacts attributable to cardiac pulsatility throughout the cardiac cycle (Enzmann and Pelc, 1992; Dagli et al., 1999). Furthermore, both regions are bordered by CSF, which exacerbates movement-related variance.

We addressed these challenges by acquiring high-resolution, cardiacgated data, which has been used successfully to examine the midbrain and other brainstem structures (Zhang et al., 2006; D'Ardenne et al., 2008, 2013). Imaging was performed on a 3.0 T GE Discovery MR750 using a Nova Medical 32-channel head coil. We acquired functional T2*-weighted echo-planar images (EPIs) across three runs with an oblique axial slice orientation [ $1.5 \mathrm{~mm}$ slice thickness with no gaps; field of view, $192 \mathrm{~mm}$; acquisition matrix, $128 \times 128$; voxel size, $1.5 \mathrm{~mm}$ isotropic; echo time (TE), $31 \mathrm{~ms}$; flip angle, $85^{\circ}$ ]. Slice acquisition was gated to each participant's cardiac cycle, such that the number of slices acquired was set to the maximum number possible within the time of two cardiac cycles [mean $\pm \mathrm{SD}$ repetition time (TR), $2.1 \pm 0.4 \mathrm{~s}$; mean $\pm \mathrm{SD}$ number of acquired slices, $24.5 \pm 4.9$ ]. This procedure minimizes cardiac pulsatility artifacts, improving signal acquisition from midbrain structures (Guimaraes et al., 1998; Zhang et al., 2006). Acquired data covered a partial volume that included the midbrain, habenula, and ventral aspects of the striatum and prefrontal cortex (PFC; Fig. 1B). The first three volumes of each functional scan were subsequently discarded.

High-resolution T1-weighted images were acquired for each participant using a spoiled gradient-recalled acquisition in steady-state (SPGR) sequence (186 axial slices; $0.9 \mathrm{~mm}$ slice thickness with no gaps; field of view, $240 \mathrm{~mm}$; acquisition matrix, $256 \times 256$; $0.9375 \mathrm{~mm}$ isotropic inplane resolution; TR, $7.20 \mathrm{~s}$; TE, $2.75 \mathrm{~s}$; flip angle, $12^{\circ}$; inversion time, 450 $\mathrm{ms})$. The SPGR images were adequate for visualizing the SN and VTA.
Task and fMRI design. We used a paradigm that consisted of randomly sequenced rewarding, aversive, and neutral events (Fig. 1A). Each event was composed of a 6-s-duration visual cue and a reinforcer that initiated $2 \mathrm{~s}$ after cue onset, except for neutral trials, for which there was no reinforcer. For reward trials, the reinforcer was $1 \mathrm{ml}$ of an individual's preferred type of juice (see below). For aversive trials, participants received an electric shock at a level that was calibrated for each individual after a titration procedure described below. Juice and shock reinforcers followed their respective cues with $100 \%$ probability; therefore, the cues deterministically predicted reinforcer delivery. Cue offset was followed by an intertrial interval (ITI) with a duration determined by a Poisson process with a mean of $8 \mathrm{~s}$, truncated at a minimum of $4 \mathrm{~s}$ and a maximum of 14 s (Berns et al., 2001).

Each type of trial occurred 20 times over the course of three scan runs, pseudorandomized so that each run consisted of either six or seven trials of each condition. The order and ITI duration were randomized across subjects. With this trial structure, the onset of each event was unpredictable and so neural responses can be interpreted as prediction errors. We used the compound visual cue-stimulus structure to minimize eventrelated head movements under the assumption that the cues would minimize startle responses. A bite bar was also used to restrict head movement. The estimated mean translational motion during task events (i.e., during the $6 \mathrm{~s}$ events) was negligible, ranging from -0.017 to 0.015 $\mathrm{mm}$ for reward trials and from -0.011 to $0.014 \mathrm{~mm}$ for aversive trials. Moreover, we expected this task structure to minimize basal anxiety levels that may otherwise occur in responses to persistent anticipation of painful stimuli.

Stimuli and procedure. Participants were told that they would be participating in an experiment designed to study reward and aversive processing. They were told that they would see three different cues while being scanned, each of which was reliably associated with the subsequent delivery of juice, electric shock, or no stimulus (neutral trials). The juice and shock cues were semantically related to the associated reinforcers (i.e., a red drop for juice and a yellow lightning bolt icon for shocks; Fig. $1 A$ ), so that no learning was required. Participants were instructed to focus on a fixation cross between trials and to minimize head movement.

Shocks were delivered from a Grass Instruments SD-9 stimulator via two electrodes to the dorsum of the participant's left foot at a mean \pm SD of $66.1 \pm 20.5 \mathrm{~V}$. A titration procedure was used to calibrate the level of shock for each individual participant before scanning (Drabant et al., 2011). Stimulation began at $0 \mathrm{~V}$ and was increased until a level was reached that was "painful and difficult to tolerate but not unbearable."

Individual $1 \mathrm{ml}$ boluses of juice were delivered from a syringe pump (Harvard Apparatus) via food-grade plastic tubes. To ensure that juice delivery was experienced as rewarding, subjects were instructed to refrain from drinking for $3 \mathrm{~h}$ before participation and were given a choice between fruit punch, apple juice, and lemonade. The sugar content of these juice options ranged from 3.2 to $3.5 \mathrm{~g} /$ fluid ounce. A one-way ANOVA 
with juice type as a factor revealed no significant differences in reward activation as a function of juice choice.

Cardiac data was collected with a finger pulse oximeter, and volume acquisition times were recorded and subsequently used in data analysis.

Data processing. Cardiac correction was performed on the fMRI data following the procedure as outlined by Guimaraes et al. (1998). Briefly, the longitudinal relaxation time constant, T1, was estimated for each voxel based on the fact that the measured signal strength varies in proportion to the exponential recovery in longitudinal magnetization from one image acquisition to the next. We estimated $\mathrm{T} 1$ as the time constant that minimized the variation in the measured signal for each voxel given the image acquisition times. We used the coefficient of variation rather than the variance of the time series as our cost metric because this produced more biologically realistic estimates of T1. The corrected fMRI signal was then computed based on the estimated $\mathrm{T} 1$ value for each voxel.

The following preprocessing steps were performed using AFNI software (Cox, 1996). Functional data were corrected for differences in slice acquisition time using Fourier interpolation. Head movement was estimated and corrected allowing six-parameter rigid body transformations. No volumes exhibited $>1 \mathrm{~mm}$ of motion in the $x, y$, or $z$ directions relative to the previous volume. Subsequently, data were spatially smoothed with a $3 \mathrm{~mm}$ FWHM Gaussian kernel. This smoothing kernel was chosen to approximately correspond to the size of the habenula and regions of interest (ROIs) within the SN and VTA. Each voxel time series was scaled and mean-centered to give units of voxel-level percentage signal change.

Functional and T1-weighted (structural) images were coregistered according to the following procedure. Structural images were rotated into the anterior commissure-posterior commissure (AC-PC) plane in each subject's native space. The whole-brain EPIs were then coregistered to the structural images using a mutual-information $3 \mathrm{D}$ rigid-body coregistration algorithm (SPM8; Wellcome Trust Centre for Neuroimaging, London, UK). The resulting transformation matrix was then used to coregister the functional and structural images in each subject's AC-PC aligned native space. Each subject's structural images were then registered to the Talairach TT_N27 template in AFNI using a 12-parameter affine transform, and this transform was then used to align subjects' functional data in group space.

Previously, we have reported midbrain results in brainstemnormalized space using a procedure described by Napadow et al. (2006). In this dataset, group alignment was comparable in either space; therefore, we report our results in standardized Talairach space in the interest of using a coordinate system that allows comparison with other studies (Talairach and Tournoux, 1988).

ROIs. Masks of the habenula and DAergic midbrain were defined in each participant's native space on T1-weighted anatomical images using ITK-Snap software (Yushkevich et al., 2006). Anatomical landmarks were identified with reference to Duvernoy's Atlas of the Human Brainstem and Cerebellum (Naidich et al., 2009). Because of white matter plexuses within the habenula, it appears brighter than surrounding thalamic tissue, which aids in visualizing the boundaries of the structure. The volume of the bilateral habenula masks were $70.7 \pm 26.6 \mathrm{~mm}^{3}$ (mean \pm $\mathrm{SD}$ ), which is consistent with volume estimates from postmortem and high-resolution structural MR studies (Ranft et al., 2010; Savitz et al., 2011; Lawson et al., 2013).

For DAergic midbrain masks, on axial slices, the superior boundary was set to the most superior slice in which the interpeduncular fossa was visible and the inferior boundary was the base of the midbrain. The interpeduncular fossa and cerebral peduncles marked the anteromedial and anterolateral mask boundaries, respectively. The posteromedial boundary was defined by the red nuclei in more superior slices and the superior cerebellar peduncles in more inferior slices. Masks were transformed into standard space, and a group mask was defined from voxels included in at least half of the individual transformed midbrain masks, totaling $1671 \mathrm{~mm}^{3}$. This mask defined the search volume of interest for analyses specific to the midbrain.

Anatomical masks of the PFC and corpus striatum were defined using the Eickhoff-Zilles macro labels in Talairach space (Eickhoff et al., 2005). Within the partial volume of acquired functional data, the PFC mask included all voxels labeled as gray matter within the frontal lobe, and the corpus striatum mask comprised voxels labeled as the caudate and putamen (which includes the nucleus accumbens) and the globus pallidum. We note that data were not acquired from the more dorsal aspects of the striatum and PFC, because we prioritized midbrain and habenula coverage with our partial volume (Fig. 1B). These masks defined the search volumes of interest for the functional connectivity analyses.

Data analysis. fMRI analyses were performed using a two-stage approach to implement a mixed model treating participants as random effects using custom MATLAB (MathWorks) code. For each participant, a general linear model was created that included one regressor of interest for each of the three trial types. Each trial was modeled as a 2-s-duration event with a boxcar function starting at the time of cue onset. Reinforcer delivery always occurred $2 \mathrm{~s}$ after cue onset (except in the case of neutral trials, for which there was no reinforcer), so this period defined the anticipatory phase of each trial. The boxcar event series were then convolved with the default hemodynamic response function of SPM. Second-order polynomial baseline regressors were included for each scan run and the six rigid-body movement parameters estimated from the motion correction step to capture low-frequency drift and additional movement-related variance, respectively. We also included the TR of each acquired volume as an additional regressor of no interest to account for any residual variance left over from the cardiac correction procedure. The model was fit using ordinary least squares for each subject's data in standard (Talairach) space, and shock and juice parameter estimates were then each contrasted with neutral parameter estimates to produce two contrast maps of interest. These contrast maps were then entered into a random-effects second-level analysis in which effects of trial type were assessed using two-tailed one-sample $t$ tests on the contrast maps. In addition, we also report results of repeated-measures one-way ANOVA tests with event type as factor on an ROI basis for the habenula and midbrain subregions.

Statistical thresholds were corrected for familywise error (FWE) as determined with the AFNI program, 3dClustSim. With a primary threshold of $t>3.23, p<0.005$ (two-tailed), the $p<0.05$ FWE-corrected cluster extent was 68 contiguous voxels for the whole search volume and 8 voxels for small volume correction (SVC) within a group mask of midbrain DA regions. We note that the small volume-corrected cluster extent deemed by this method for the midbrain was more conservative than correction determined using nonparametric permutation tests (Nichols and Holmes, 2002).

$\beta$ series correlation analyses were conducted to assess changes in functional connectivity (Rissman et al., 2004). This was accomplished by sequentially modeling each event as a separate regressor, resulting in a set of $20 \beta$ coefficients (i.e., a $\beta$ series) for each trial type. $\beta$ series were generated on an ROI basis for the habenula and functionally active clusters within the midbrain and on a voxelwise basis for voxels within the PFC and corpus striatum masks. Midbrain ROI $\beta$ series were created by averaging the $\beta$ series across voxels in the ROI, weighted by the distance of the voxel from the center of the ROI (i.e., central voxels contributed more to the $\beta$ series estimation than peripheral voxels). To avoid spurious correlations driven by high-frequency noise in the time series, trials with $\beta$ values that deviated $>3$ SDs from the mean of its $\beta$ series were excluded from analysis. This led to the exclusion of $<0.5 \%$ of the total trials and did not qualitatively change the pattern of the results.

Correlation coefficients were transformed to be normally distributed using Fisher's $r$-to- $Z$ transformation. Changes in functional connectivity were assessed using repeated-measures one-way ANOVAs with event type as factor and paired-sample $t$ tests performed on the transformed correlation coefficients. For midbrain functional connectivity with voxels in the PFC and corpus striatum, comparisons were restricted to shock and neutral $\beta$ series correlations and statistics were FWE corrected to $p<$ 0.05 for these search volumes of interest.

All statistical parametric maps shown in the figures are overlaid on the T1-weighted Talairach-Tournoux template (based on the Montreal Neurological Institute Colin 27 Average Brain) for visualization purposes. 
Table 1. Summary of main effects contrasts and midbrain functional connectivity

\begin{tabular}{|c|c|c|c|c|c|c|}
\hline Brain region & $\mathrm{R} / \mathrm{L}$ & Voxels & $t$ & $x$ & $y$ & $z$ \\
\hline \multicolumn{7}{|l|}{ Shock versus neutral trials } \\
\hline Midbrain, VTA ${ }^{a}$ & $\mathrm{R}$ & 8 & 4.31 & 8 & -14 & -8 \\
\hline Midbrain, $\mathrm{SN}^{a}$ & L & 14 & 5.06 & -11 & -17 & -11 \\
\hline Brainstem & L & 649 & 8.66 & -9 & -20 & -6 \\
\hline Habenula & L & $*$ & 5.88 & -2 & -29 & 0 \\
\hline PAG/superior colliculus & R & $*$ & 7.94 & 5 & -26 & -5 \\
\hline $\begin{array}{l}\text { Ventral posterolateral thalamic } \\
\text { nucleus }\end{array}$ & L & * & 3.84 & -15 & -15 & 6 \\
\hline Caudate & $\mathrm{R}$ & 80 & 4.97 & 11 & 8 & 6 \\
\hline Inferior frontal gyrus & L & 1607 & 7.32 & -33 & 29 & 0 \\
\hline Insula & L & $*$ & 5.51 & -39 & 14 & 0 \\
\hline Insula & $\mathrm{R}$ & 1982 & 7.04 & 38 & 2 & -9 \\
\hline Medial frontal gyrus & L & 378 & -7.60 & -3 & 47 & -14 \\
\hline Middle frontal gyrus & L & 82 & -5.24 & -39 & 39 & -11 \\
\hline Subcallosal gyrus (frontal lobe) & L & 87 & 5.32 & -23 & 6 & -12 \\
\hline \multirow[t]{4}{*}{ Inferior temporal gyrus } & L & 193 & -5.41 & -60 & -24 & -15 \\
\hline & L & 90 & -5.17 & -56 & -15 & -18 \\
\hline & $\mathrm{R}$ & 121 & 4.48 & 56 & -62 & -3 \\
\hline & R & 155 & -5.06 & 59 & -8 & -17 \\
\hline Middle tempora & L & 107 & 4.45 & -48 & -54 & -2 \\
\hline Lingual gyrus & L & 109 & 5.09 & -26 & -87 & -5 \\
\hline \multirow[t]{2}{*}{ Inferior occipital gyrus } & $\mathrm{R}$ & 314 & 5.13 & 33 & -86 & -11 \\
\hline & R & 103 & 4.50 & 32 & -89 & -5 \\
\hline Brainstem (pons) & R & 132 & 5.87 & 8 & -9 & -23 \\
\hline \multirow[t]{3}{*}{ Cerebellum } & L & 134 & 5.71 & -3 & -53 & -18 \\
\hline & L & 139 & 5.43 & -24 & -83 & -15 \\
\hline & $\mathrm{R}$ & 103 & 5.24 & 23 & -29 & -27 \\
\hline \multicolumn{7}{|l|}{ Juice versus neutral trials } \\
\hline \multirow[t]{2}{*}{ Putamen } & L & 559 & 7.49 & -24 & 6 & 3 \\
\hline & R & 490 & 7.11 & 27 & -6 & -5 \\
\hline \multirow[t]{2}{*}{ Cerebellum } & L & 258 & 7.46 & -18 & -62 & -20 \\
\hline & R & 106 & 5.08 & 17 & -60 & -21 \\
\hline Parahippocampal gyrus & $\mathrm{R}$ & 183 & -5.45 & 23 & -35 & -14 \\
\hline Middle frontal gyrus & L & 248 & -5.11 & -44 & 39 & -5 \\
\hline Pulvinar/thalamus & $\mathrm{R}$ & 80 & -5.66 & 20 & -32 & 4 \\
\hline \multicolumn{7}{|l|}{$\begin{array}{l}\text { VTA functional connectivity } \\
\text { (shock vs neutral trials) }\end{array}$} \\
\hline $\begin{array}{l}\text { Habenula (anatomically } \\
\text { defined ROl in native space) }\end{array}$ & L & $11 \pm 1.1$ & 3.09 & - & - & - \\
\hline Putamen $^{a}$ & R & 29 & 4.93 & 26 & -6 & 7 \\
\hline $\begin{array}{l}\text { Medial frontal gyrus/ } \\
\text { anterior cingulate }{ }^{a}\end{array}$ & R & 32 & 4.78 & 5 & 48 & 13 \\
\hline
\end{tabular}

SN functional connectivity $\mathrm{GP}^{a, b}$ (shock vs neutral trials)
Talairach coordinates and $t$ statistics are reported for the peak voxel within each cluster (or local maxima within a cluster, indicated by indented regions). Unless noted otherwise, a primary threshold of $p<0.005$ was used and clusters were FWE corrected at $p<0.05$ for the search volume of interest. Brain regions were estimated using the Talairach daemon database (http://www.talairach.org) and with reference to an anatomical atlas (Naidich et al., 2009). * indicates a subpeak within the cluster listed directly above. L, left; R, right.

${ }^{a}$ Small volume corrected at $p<0.05$ within an anatomically defined mask of interest.

${ }^{b}$ Cluster reported is $p<0.05$ corrected using a primary threshold of $p<0.01$.

\section{Results}

To identify regions involved in motivational processing, we estimated BOLD response amplitudes to rewarding and aversive events (cues followed by juice delivery and electric footshock, respectively) contrasted with activity elicited by neutral events (cues with no reinforcer delivery). Contrasting responses to shock and neutral cues revealed robust activation within a number of brain regions (Table 1). In the forebrain, the largest clusters of activity were found in bilateral insula, a region associated with anticipating and processing nociceptive information (Ploghaus et al., 1999). The caudate also exhibited significant activation, in line with the known role of this region in predicting aversive

\section{A Shock $>$ Neutral}

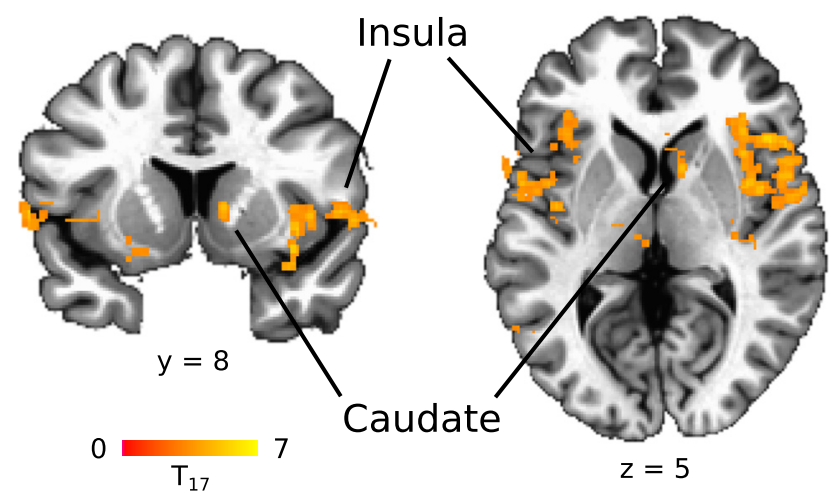

\section{B Juice $>$ Neutral}

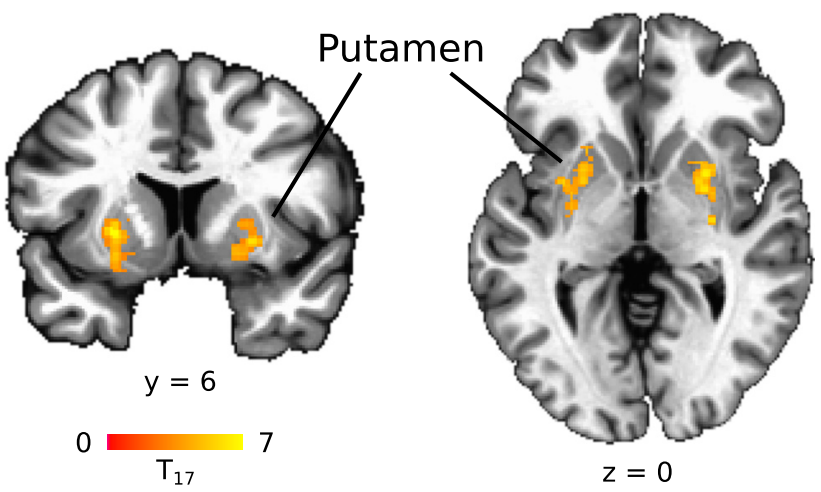

Figure 2. Whole search volume activity related to aversive and reward processing. $A$, Brain areas significantly activated in the contrast of shock and neutral cues included the bilateral insula and right caudate, shown in both coronal and axial views. $\boldsymbol{B}$, Brain areas significantly activated in the contrast of juice and neutral cues included the bilateral ventral striatum (putamen), shown in both coronal and axial views. Statistical maps were voxel-level thresholded at $p<0.005$ and cluster-size FWE corrected at $p<0.05$ for the whole search volume. For a complete list of activated regions, see Table 1.

events (Delgado et al., 2008). Insula and caudate activations are shown in Figure $2 A$.

Statistically significant activation was also observed in a cluster of voxels that encompassed rostral aspects of the cerebellum, dorsal midbrain, and thalamic areas. Peak responses in this cluster were in the periaqueductal gray $(\mathrm{PAG})$ /superior colliculus, thalamus, and left habenula. Thalamic nuclei in close proximity to the habenula are commonly activated by noxious stimuli in fMRI studies, such as the medial dorsal, ventral anterior, and ventral lateral nuclei of the thalamus (Peyron et al., 2000; Shelton et al., 2012). In an effort to more accurately resolve signal attributed to the habenula from surrounding structures, we estimated the response averaged over voxels within habenula masks defined individually in each participant's native space. This ROI analysis confirmed the group activation map result: the left habenula was activated robustly by aversive relative to neutral events $\left(t_{(17)}=\right.$ $5.16, p<0.0001$; Fig. $3 A, B)$. This effect was less pronounced in the right habenula $\left(t_{(17)}=2.56, p=0.02\right)$. Although we had no a priori hypothesis regarding laterality, we note that the increased activation observed in the left habenula was significantly greater than in the right $\left(t_{(17)}=3.99, p<0.001\right)$. Therefore, subsequent analyses focused on the left habenula as the ROI. 
A

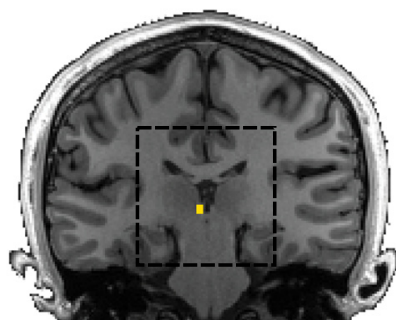

$y=-27$ (native space)

C

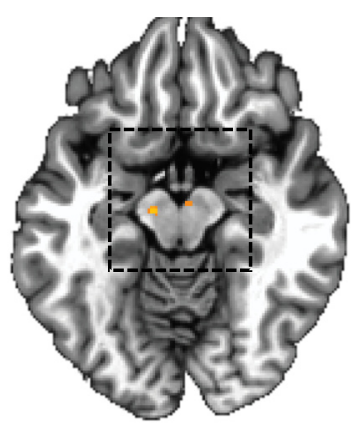

$\mathrm{z}=-11$

D

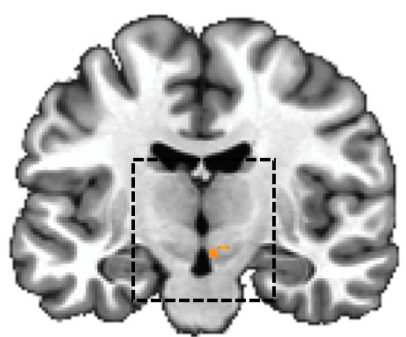

$y=-13$

F

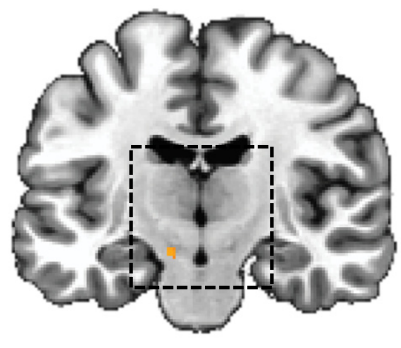

$y=-15$

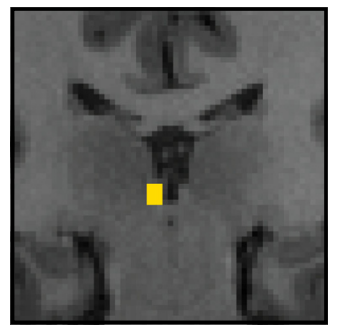

Habenula

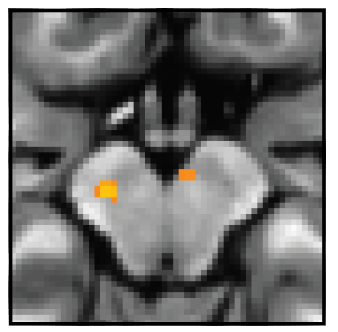

SN \& VTA

\section{B}

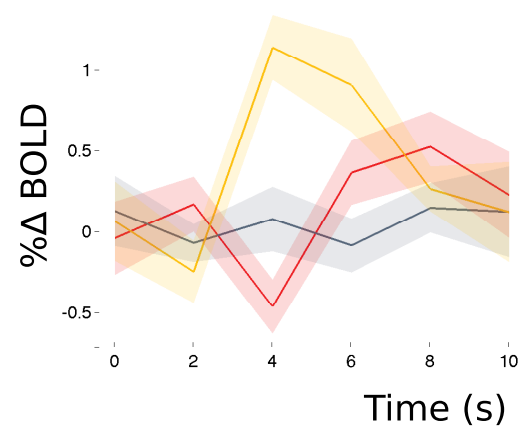

7
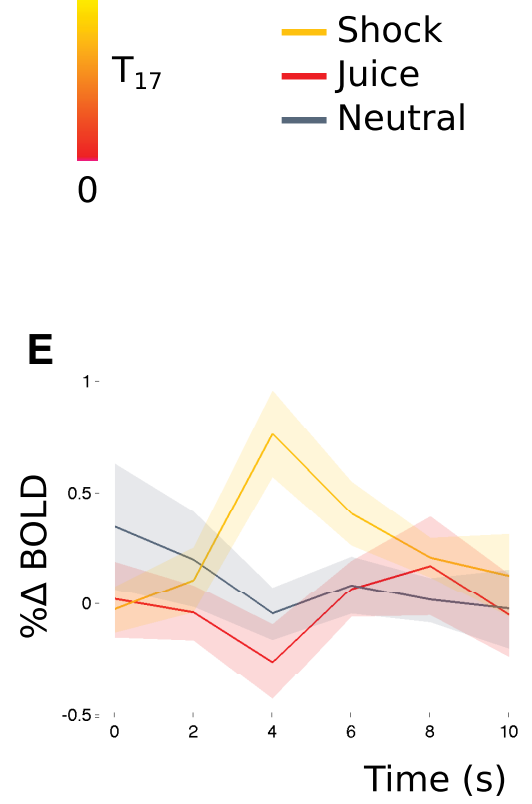

G

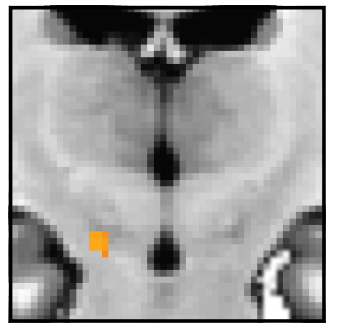

SN

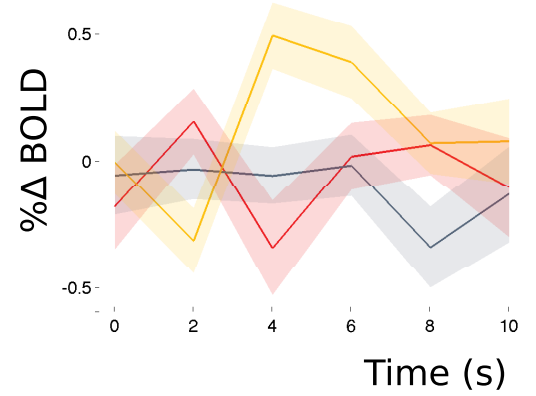

Figure 3. Habenula and midbrain areas activated by aversive events. $A$, Left habenula ROI mask for a representative subject, shown in a coronal view. Bilateral habenula ROIs were anatomically defined in each subject's native space, and responses to each event type were estimated on an ROl basis. $\boldsymbol{B}, B O L D$ time courses starting at cue onset for the left habenula. $\boldsymbol{C}, \boldsymbol{D}, \boldsymbol{F}$, Midbrain areas activated by aversive events. Two clusters within the DAergic midbrain exhibited significant activity in the contrast of shock and neutral cues, one within the SN and the other in the VTA, shown in axial $(\boldsymbol{C})$ and coronal $(\boldsymbol{D}, \boldsymbol{F})$ views. $\boldsymbol{E}, \mathbf{G}$, BOLD time courses starting at cue onset for the VTA $(\boldsymbol{E})$ and SN $(\boldsymbol{G})$. Time courses were estimated using linear piecewise regression. Shaded area shows the SEM.

To assess whether the observed activation within the habenula was specific to negative motivational processing, we also examined responses to juice cues in relation to shock and neutral cues. A repeated-measures one-way ANOVA with event type as factor revealed a significant effect of event type $\left(F_{(2,34)}=11.5, p=2 \times\right.$ $10^{-4}$ ), and subsequent $t$ tests showed that the response to juice was significantly less than $\operatorname{shock}\left(t_{(17)}=-2.88, p=0.01\right)$ and did not differ from neutral $\left(t_{(17)}=1.26, p=0.2\right)$. These results indicate that the habenula was activated selectively by negative, but not positive, motivational information in our task.

Within the DAergic midbrain, contrasting shock versus neutral trials revealed significant activation within two clusters (Fig. 
$3 C-G$; Table 1). One cluster fell within the VTA, and the other was located more laterally within the $\mathrm{SN}$. To assess the responses within these aversive-activated ROIs to positive motivational information, we examined activation to juice cues compared with neutral and shock cues. A repeated-measures one-way ANOVA with event type as factor was significant for both ROIs (VTA, $\left.F_{(2,34)}=11.1, p=2 \times 10^{-4} ; \mathrm{SN}, F_{(2,34)}=13.2, p<1 \times 10^{-4}\right)$. For the VTA, $t$ tests showed that this effect was driven by heightened responses to shock relative to juice and neutral cues (shock vs juice, $t_{(17)}=3.76, p=0.002$; juice vs neutral, $\left.t_{(17)}=-0.59, p=0.6\right)$. The same pattern of results was observed for the SN (shock vs juice, $t_{(17)}=3.70, p=0.002$; juice vs neutral, $t_{(17)}=0.83, p=0.4$ ). Thus, we identified regions within the DAergic midbrain that were modulated selectively by negative motivational information.

We also identified regions sensitive to just rewards by contrasting responses to juice and neutral cues. This contrast revealed robust activity within the ventral striatum (Fig. $2 B$ ), an area known to be involved in processing rewards (McClure et al., 2003), as well as other forebrain regions (Table 1). Surprisingly, this contrast did not yield significant activity within the midbrain, even with SVC. We address the null finding regarding midbrain reward responses in Discussion.

\section{Midbrain functional connectivity}

Recent work in rodents has identified a direct pathway between the habenula and VTA that may account for the coactivation of these structures in the current experiment (Lammel et al., 2012). If habenula input were driving the aversion responses observed in the midbrain, then trial-by-trial variability in responses amplitudes in these two regions should covary while aversive information is being processed. To determine whether this was the case, we correlated trial-by-trial response amplitudes ( $\beta$ series; Rissman et al., 2004) between the habenula and VTA, as well as between the habenula and SN, separately for each event type (Fig. 4). A repeated-measures one-way ANOVA with event type as factor yielded no significant differences in habenula functional connectivity with the $\mathrm{SN}\left(F_{(2,34)}=0.10, p=0.91\right)$. However, this test did reveal significant differences in habenula functional connectivity with the VTA across event types $\left(F_{(2,34)}=5.6, p=\right.$ $0.008)$. Post hoc $t$ tests showed that this effect was driven by increased functional connectivity (i.e., a higher correlation) during shock relative to neutral trials $\left(t_{(17)}=3.09, p=0.007\right)$ and that connectivity during juice trials did not significantly differ from neutral $\left(t_{(17)}=1.89, p=0.08\right)$ or shock trials $\left(t_{(17)}=-1.61, p=\right.$ $0.13)$.

We conducted two additional analyses to probe the anatomical specificity of the observed increase in functional connectivity between the habenula and VTA during shock relative to neutral trials. The first control analysis was designed to test the possibility that the VTA exhibited this relationship with the greater thalamic/epithalamic region rather than being specific to the habenula. To test this possibility, we defined a set of control ROIs that were the same size and shape as each subject's left habenula ROI but shifted $6 \mathrm{~mm}$ in the anterior, posterior, left, right, and inferior directions (a superior ROI fell outside the range of acquired data for some subjects). We then calculated $\beta$ series correlations with the VTA for each control ROI. None of the control ROIs exhibited significant changes in functional connectivity with the VTA (all $p$ values $>0.05$, two-tailed $t$ tests). Furthermore, the increase in functional connectivity with the VTA during shock relative to neutral trials was significantly greater for the habenula than for most of the control ROIs (anterior, $t_{(17)}=1.74$, $p=0.05$; inferior, $t_{(17)}=1.94, p=0.03$; left, $t_{(17)}=2.77, p=$

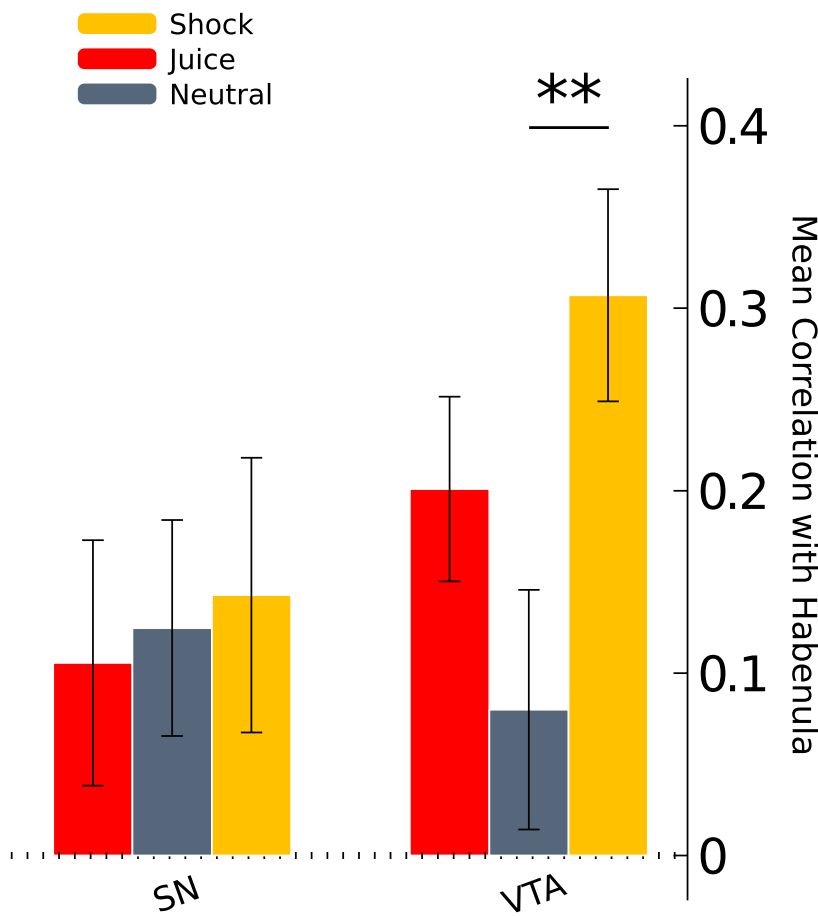

Figure 4. Midbrain functional connectivity with the habenula. $\beta$ series correlations were calculated between the habenula and $\mathrm{SN}$, as well as between the habenula and VTA, separately for each event type (habenula, SN, and VTA ROIs are shown in Fig. 3). The bars above plot the mean resulting $z$-transformed $\beta$ series correlation coefficients. Error bars indicate the SEM. ${ }^{* *} p<0.01$.

0.007 ; posterior, $t_{(17)}=0.73, p=0.2$; right, $t_{(17)}=1.53, p=$ 0.07 , one-tailed $t$ tests). These results suggest that the aversiverelated change in functional connectivity with the VTA was specific to the habenula rather than the general thalamic/epithalamic region.

The second control analysis was designed to assess the specificity of the aversive-activated VTA area in this relationship. To this end, we calculated $\beta$ series correlations between the habenula and ROIs of the same size and shape as the VTA ROI but shifted $6 \mathrm{~mm}$ in the anterior, posterior, left, right, inferior, and superior directions. No functional connectivity changes were observed between the habenula and any of these control ROIs surrounding the VTA (all $p$ values $>0.05$, two-tailed $t$ tests). Moreover, the increase in functional connectivity was significantly greater for the VTA compared with all but one of the adjacent control ROIs (anterior, $t_{(17)}=3.52, p=0.001$; inferior, $t_{(17)}=2.16, p=0.02$; left, $t_{(17)}=1.94, p=0.03$; posterior, $t_{(17)}=1.92, p=0.04$; right, $t_{(17)}=2.85, p=0.006$; superior, $t_{(17)}=1.35, p=0.1$; one-tailed $t$ tests). Collectively, results from these two control analyses demonstrate that the functional coupling between the habenula and VTA subregion was privileged, with a remarkable degree of anatomical specificity.

Next, we examined aversive-related functional connectivity between the midbrain and DA target structures. For these analyses, we focused exclusively on the contrast of shock and neutral events, and we confined our voxelwise search volume to the PFC and corpus striatum, which are the primary targets of midbrain DA projections (Lewis and Sesack, 1997). The aims of this analysis were twofold. First, although it is known that midbrain DA signals modulate activity in these forebrain regions to update value representations in the context of rewards, it is less clear how these structures interact in the context of aversive events (Brooks 
and Berns, 2013). Therefore, we were interested in examining which (if any) DA target structures are functionally coupled with the midbrain while processing aversive information.

Second, we were interested in comparing the patterns of functional connectivity observed for the VTA and SN to identify the diversity of aversive-related responses across the midbrain. In nonhuman primates, there is evidence both for and against subregional variability in midbrain DA areas in response to aversive stimuli (Matsumoto and Hikosaka, 2009b; Fiorillo et al., 2013). If the SN and VTA were processing similar information related to aversive events in our task, then we reasoned that they should exhibit comparable patterns of functional connectivity with target structures. Conversely, if the SN and VTA displayed different patterns of connectivity, this would suggest that they are components of distinct functional circuits.

We began by investigating functional connectivity between the VTA and forebrain target regions. During shock relative to neutral trials, the VTA exhibited increased functional connectivity with a cluster in the medial PFC, which bordered the medial frontal gyrus and anterior cingulate cortex, as well as a cluster within the right putamen. Both clusters are shown in Figure $5 B$ and reported in Table 1.

Unlike the VTA, no increases in functional connectivity were observed between forebrain regions and the $\mathrm{SN}$. However, the SN did exhibit decreased functional connectivity with a cluster centered within the external segment of the globus pallidus (GPe), close to the border of the GPe and internal segment of the globus pallidus (GPi; Fig. 5C; Table 1). This decreased functional connectivity suggests a functionally antagonistic re-

lationship between these regions during aversive processing, such that greater responses to shock cues within the SN were concurrent with smaller responses in the GPe and vice versa. Although the relationship between the SN and GPe was significant in voxels at $p<0.005$ (the primary threshold used for all other reported analyses), it survived cluster-size correction for multiple comparisons only when the voxel threshold was set to $p<0.01$.

Finally, to directly test for differential patterns of connectivity across the midbrain, we contrasted the functional connectivity difference maps generated using the VTA and SN as seed regions. This analysis yielded significant differences in three areas, all in the direction of greater VTA connectivity during shock relative to neutral trials compared with the SN. Clusters were located within the medial PFC (peak voxel $t_{(17)}=6.61, p<0.05$ corrected, $x=$ $-27, y=56, z=13$ ), putamen (peak voxel $t_{(17)}=4.44, p<0.05$ corrected, $x=24, y=2, z=-3)$, and a region bordering the GPe and GPi (peak voxel $t_{(17)}=5.09, p<0.05$ corrected, $x=14, y=$ $-6, z=4$; cluster center of mass, $x=14, y=-4, z=3)$. The
B VTA Connectivity
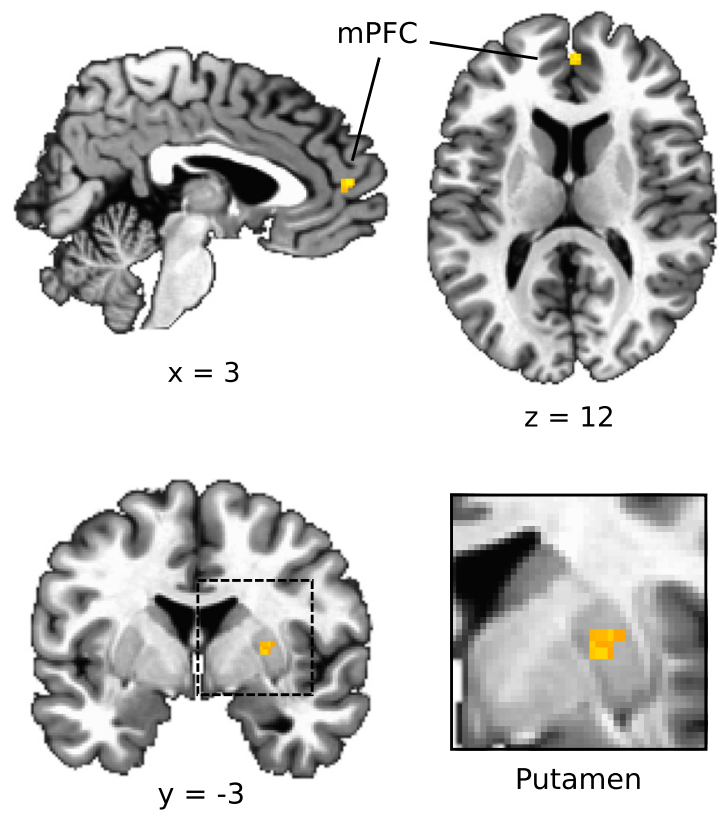

Putamen
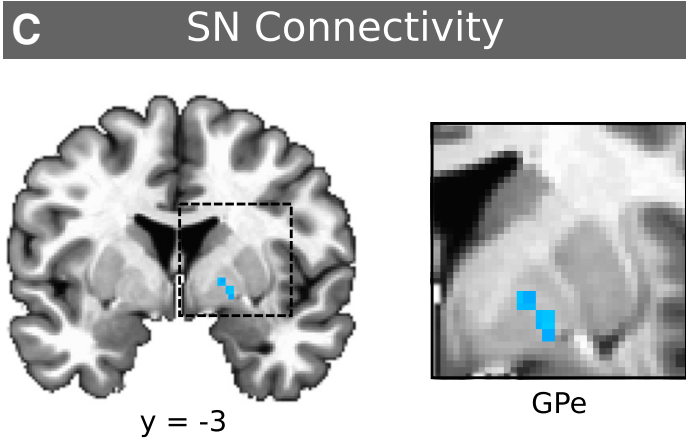

$\mathrm{GPe}$

Figure 5. Midbrain circuitry involved in aversive processing. $\boldsymbol{A}$, Schematic of midbrain circuits identified based on functional connectivity results. Connections are annotated with figure references. Lines with arrowheads depict increased functional connecwith a cluster bordering the medial frontal gyrus and anterior cingulate cortex (top row, shown in a sagittal view on the left and view on the right) and in the striatum within the putamen (second row, shown in a coronal view). C, Conversely, the SN exhibited decreased connectivity with a cluster centered in the GPe during aversive events (bottom row, shown in a coronal view). Hab, Habenula; mPFC, medial PFC; Str, striatum.

GPe/GPi border cluster overlapped with the GPe region exhibiting decreased functional connectivity with the SN (shown in Fig. $5 C$ ), and the medial PFC and putamen areas generally correspond to the regions identified as functionally coupled with the VTA (Fig. 5B).

Overall, the functional connectivity results suggest that aversive processing activated two distinct midbrain pathways, which are schematized in Figure 5A. One of these pathways included the VTA and habenula, in addition to the medial PFC and putamen. The other pathway involved the SN, which exhibited antagonistic functional coupling with the GPe. These differential connectivity patterns suggest the existence of separable midbrain circuits that are responsive to aversive stimuli.

\section{Discussion}

We examined human midbrain responses to motivational events to identify DA-related circuitry involved in aversive processing. The midbrain DA system has most commonly been theorized to 
be involved exclusively in encoding reward-related information (Schultz et al., 1997; Fiorillo, 2013), yet we observed increased activation within the DAergic midbrain during aversive events. By itself, this finding begs for a reconsideration of DA function in behavioral control and particularly the role of DA in behaviors such as addiction (see below).

Previous fMRI studies have not observed midbrain responses to other forms of negative events, such as monetary losses (D'Ardenne et al., 2008). We suspect that our success resulted from the fact that we used more intense and salient stimuli than have been used previously. Additionally, previous studies measured only from the rostral midbrain (D'Ardenne et al., 2008), whereas the imaging protocol we used measured from the whole midbrain, allowing VTA and SN to be sampled in their entirety.

The habenula was strongly activated by aversive events and also exhibited increased functional coupling with the VTA in response to aversive stimuli. Habenula-VTA coupling also marginally increased during juice trials. These results are consistent with aversive information being communicated in the habenulaVTA pathway. Specifically, juice has a zero or negative value on an "aversion" scale. If the habenula-VTA circuit communicates this information, then reward-related activity in the habenula and VTA should be small (Fig. 3), and the circuit should communicate this information as evidenced by increased functional connectivity (Fig. 4). This result also suggests that habenula-VTA activity is continuous (positive for shocks, zeros for juice) and cross-modal. This interpretation is consistent with animal research showing that the lateral habenula signals negative motivational information to the midbrain DA system and that these signals are essential for avoidance learning and behaviors (Thornton and Bradbury, 1989; Matsumoto and Hikosaka, 2007; Hikosaka, 2010). Given the low temporal resolution of BOLD, we cannot make inferences about the directionality of habenula-VTA communication. Nevertheless, our findings show that habenula-VTA interactions are involved in aversive processing in humans.

We also found that the VTA was functionally coupled with the medial PFC and putamen during aversive stimulation. Increased DA release in both of these regions has been associated with aversive processing (Menon et al., 2007; Lammel et al., 2012). Overall, we identified a network through which aversive information may be conveyed from the habenula to DAergic nuclei and onward to DA target structures. Future research should explore how this network supports aversive learning.

Some caution is necessary when interpreting the increased BOLD responses we identified in the midbrain to aversive stimuli (Düzel et al., 2009). In animals, reward-predicting DA cells are indirectly inhibited by the lateral habenula via the rostromedial tegmental nucleus (RMTg), a GABAergic nucleus located at the caudal tail of the VTA (Jhou et al., 2009; Hong et al., 2011). At least some of these DA cells then project to the nucleus accumbens to facilitate reward learning (Lammel et al., 2012). It is possible that aversive-related habenula-VTA connectivity was mediated by a human analog of the RMTg, although we found no evidence for such a relationship.

Another possibility, which is more parsimonious given our results, is that activation and functional coupling of the habenula and VTA reflect their direct communication. In rodents, a direct habenula-VTA pathway supports conditioned place aversion via DAergic projections to the medial PFC (Lammel et al., 2012). The pattern of functional connectivity we observed between the VTA, habenula, and medial PFC is consistent with this pathway. However, we note that there is arguably no rodent homolog to the medial PFC cluster we identified (Wise, 2008).
Aversive events also activated a subregion of the SN. Aversiveexcited DA cells in monkeys have been identified in dorsolateral areas of the DAergic midbrain relative to aversive-inhibited cells (Matsumoto and Hikosaka, 2009b). The SN activation we observed may reflect activity from a homologous population of DA cells. The SN exhibited decreased functional connectivity with the GPe during aversive processing in our study. Tracer studies indicate that a small number of DAergic projections target the GPe, which may underlie our observed functional connectivity between these regions (Smith et al., 1989, Smith and Kieval, 2000). Alternatively, SN-GPe activity may reflect activation of the striatopallidal indirect pathway rather than motivation-related processing within DAergic portions of the SN. The striatopallidal indirect pathway, traditionally known for motor inhibition, facilitates avoidance behaviors and learning from punishments (Gerfen, 1992; Hikida et al., 2010; Kravitz et al., 2012). When activated, tonically active GPe is suppressed and the SN pars reticulata (SNr) is excited (Alexander and Crutcher, 1990). It is not possible to distinguish BOLD activity in the SNr or the DAergic SN pars compacta as the nuclei interdigitate (Lewis and Sesack, 1997). However, the observed negative correlation in BOLD responses between the SN and GPe is most consistent with $\mathrm{SNr}-\mathrm{GPe}$ striatopallidal indirect pathway circuitry.

The extent to which striatal BOLD signals reflect aversive processing seems to depend on the type of stimulus used. Although results have been mixed for monetary losses-some studies report increases (Jensen et al., 2007; Seymour et al., 2007; Delgado et al., 2008) and others report decreases or no change in striatal activity (Delgado et al., 2000; Breiter et al., 2001; Yacubian et al., 2006; Tom et al., 2007; Guitart-Masip et al., 2011)_fMRI studies using shocks or noxious heat have generally found increases in striatal activation (Jensen et al., 2003, 2007; Seymour et al., 2005, 2007; Menon et al., 2007; Delgado et al., 2008). Consistent with these latter studies, we found that aversive events were associated with increased activity in the striatum (mid-caudate). VTA-putamen connectivity analysis suggested that signals specific to aversive information are communicated between these regions. Tracer studies in monkeys have shown that the putamen receives input from DA cells located throughout the VTA and SN, whereas putamen projections to midbrain DA areas are confined primarily to the SN (Haber et al., 2000). Based on this anatomy, it is possible that our observed functional connectivity reflects VTA signals relayed to the putamen.

Consistent with past studies, we found activation in the ventral striatum in response to juice delivery (Berns et al., 2001; McClure et al., 2003, 2007; O’Doherty et al., 2006). These responses were restricted to the putamen, in which neurons that signal the occurrence of juice reward have been found to be located most densely in monkeys (Klein and Platt, 2013). We found no evidence that juice reward evokes responses in the DAergic midbrain in our data. Previous fMRI studies found midbrain activation that scaled positively with reward prediction error (D'Ardenne et al., 2008), preference for primary rewards (O'Doherty et al., 2006), and reward anticipation (Wittmann et al., 2005; Krebs et al., 2011). Unlike these studies, rewards in our paradigm were intermixed with shocks, which may have qualitatively changed reward evaluations. Other studies report that evaluative processing is altered in contexts involving shocks (Vlaev et al., 2009), particularly when another reinforcer is intermixed with electric shock (Delgado et al., 2006). Anticipation or threat of shock is used commonly to induce stress (Drabant et al., 2011; Berghorst et al., 2013), and several studies demonstrate that stress blunts reward sensitivity and reward-related neural activity (Por- 
celli et al., 2012; Berghorst et al., 2013; Treadway et al., 2013). It is possible that anticipation of shock in our paradigm diminished responses to rewards.

The lack of reward-related midbrain activation rules out an alternative explanation of the activity we observed in the VTA in response to aversive events. Recently, it has been suggested that paradigms in which rewards and punishments are intermixed may elicit excitatory responses in DA neurons to aversive cues because of their physical similarity to reward cues (Schultz, 2013). At least for our data, this interpretation cannot account for the aversive activations we observed in the midbrain because we did not observe responses to rewards. An ambiguity account would predict that midbrain responses to reward should be at least as large as responses to aversive stimuli.

The rewarding (juice) and aversive (shock) stimuli we used are primary reinforcers that have been shown to elicit the affective responses of interest (McClure et al., 2003; Berns et al., 2006; D’Ardenne et al., 2008; Delgado et al., 2008). We selected these stimuli to facilitate comparison with animal studies that used footshock (Brischoux et al., 2009) and injection of Formalin (Lammel et al., 2011). However, this choice of stimuli sacrifices benefits of using stimuli from the same sensory modality. We also did not equate stimuli for intensity. Therefore, we cannot rule out the possibility that the responses we observed were related to differences in attention, sensory intensity, or salience rather than differences in motivational value. Controlling for intensity would allow us to more meaningfully contrast amplitudes of BOLD responses to rewarding and aversive events (cf. Fiorillo et al., 2013). It was not our intention to compare response amplitudes; our goal instead was to determine which regions of the DAergic midbrain respond at all to positive and negative stimuli. Equating for stimulus intensity and modality would address interesting questions, but ones that are beyond the scope of this study.

In monkeys, there is evidence both for and against functional diversity across midbrain DA areas with respect to aversive processing (Matsumoto and Hikosaka, 2009b; Fiorillo et al., 2013). In this study, we found evidence in favor of functional diversity, in that aversive processing activated midbrain subregions that exhibited unique patterns of functional connectivity. Identifying this functional circuitry in humans opens the door to understanding how distinct networks support the diversity of behaviors associated with the DA system. Our findings also challenge the working model of the role of DA in addiction-that drugs of abuse exert their reinforcing effects by increasing DA signaling (Redish, 2004). We show that at least a subset of the human DAergic midbrain is activated by aversive events. This suggests that the effect of systemically increasing DA levels, as drugs of abuse do, is more complex than thought previously. It is likely that addiction involves an interaction between DA networks associated with different motivational properties, and understanding these interactions may lead to a more nuanced view of addiction and a better understanding of the association between stress and drug abuse.

\section{References}

Abercrombie ED, Keefe KA, DiFrischia DS, Zigmond MJ (1989) Differential effect of stress on in vivo dopamine release in striatum, nucleus accumbens, and medial frontal cortex. J Neurochem 52:1655-1658. CrossRef Medline

Alexander GE, Crutcher MD (1990) Functional architecture of basal ganglia circuits: neural substrates of parallel processing. Trends Neurosci 13:266271. CrossRef Medline

Berghorst LH, Bogdan R, Frank MJ, Pizzagalli DA (2013) Acute stress selec- tively reduces reward sensitivity. Front Hum Neurosci 7:133. CrossRef Medline

Berns GS, McClure SM, Pagnoni G, Montague PR (2001) Predictability modulates human brain response to reward. J Neurosci 21:2793-2798. Medline

Berns GS, Chappelow J, Cekic M, Zink CF, Pagnoni G, Martin-Skurski ME (2006) Neurobiological substrates of dread. Science 312:754-758. CrossRef Medline

Breiter HC, Aharon I, Kahneman D, Dale A, Shizgal P (2001) Functional imaging of neural responses to expectancy and experience of monetary gains and losses. Neuron 30:619-639. CrossRef Medline

Brischoux F, Chakraborty S, Brierley DI, Ungless MA (2009) Phasic excitation of dopamine neurons in ventral VTA by noxious stimuli. Proc Natl Acad Sci U S A 106:4894-4899. CrossRef Medline

Bromberg-Martin ES, Matsumoto M, Hikosaka O (2010) Dopamine in motivational control: rewarding, aversive, and alerting. Neuron 68:815-834. CrossRef Medline

Brooks AM, Berns GS (2013) Aversive stimuli and loss in the mesocorticolimbic dopamine system. Trends Cogn Sci 17:281-286. CrossRef Medline

Christoph GR, Leonzio RJ, Wilcox KS (1986) Stimulation of the lateral habenula inhibits dopamine-containing neurons in the substantia nigra and ventral tegmental area of the rat. J Neurosci 6:613-619. Medline

Cox RW (1996) AFNI: software for analysis and visualization of functional magnetic resonance neuroimages. Comput Biomed Res 29:162-173. CrossRef Medline

Dagli MS, Ingeholm JE, Haxby JV (1999) Localization of cardiac-induced signal change in fMRI. Neuroimage 9:407-415. CrossRef Medline

D'Ardenne K, McClure SM, Nystrom LE, Cohen JD (2008) BOLD responses reflecting dopaminergic signals in the human ventral tegmental area. Science 319:1264-1267. CrossRef Medline

D’Ardenne K, Lohrenz T, Bartley KA, Montague PR (2013) Computational heterogeneity in the human mesencephalic dopamine system. Cogn Affect Behav Neurosci 13:747-756. CrossRef Medline

Delgado MR, Nystrom LE, Fissell C, Noll DC, Fiez JA (2000) Tracking the hemodynamic responses to reward and punishment in the striatum. J Neurophysiol 84:3072-3077. Medline

Delgado MR, Labouliere CD, Phelps EA (2006) Fear of losing money? Aversive conditioning with secondary reinforcers. Soc Cogn Affect Neurosci 1:250-259. CrossRef Medline

Delgado MR, Li J, Schiller D, Phelps EA (2008) The role of the striatum in aversive learning and aversive prediction errors. Philos Trans R Soc Lond B Biol Sci 363:3787-3800. CrossRef Medline

Drabant EM, Kuo JR, Ramel W, Blechert J, Edge MD, Cooper JR, Goldin PR, Hariri AR, Gross JJ (2011) Experiential, autonomic, and neural responses during threat anticipation vary as a function of threat intensity and neuroticism. Neuroimage 55:401-410. CrossRef Medline

Düzel E, Bunzeck N, Guitart-Masip M, Wittmann B, Schott BH, Tobler PN (2009) Functional imaging of the human dopaminergic midbrain. Trends Neurosci 32:321-328. CrossRef Medline

Eapen M, Zald DH, Gatenby JC, Ding Z, Gore JC (2011) Using highresolution $\mathrm{MR}$ imaging at $7 \mathrm{~T}$ to evaluate the anatomy of the midbrain dopaminergic system. AJNR Am J Neuroradiol 32:688-694. CrossRef Medline

Eickhoff SB, Stephan KE, Mohlberg H, Grefkes C, Fink GR, Amunts K, Zilles K (2005) A new SPM toolbox for combining probabilistic cytoarchitectonic maps and functional imaging data. Neuroimage 25:1325-1335. CrossRef Medline

Enzmann DR, Pelc NJ (1992) Brain motion: measurement with phasecontrast MR imaging. Radiology 185:653-660. CrossRef Medline

Fadok JP, Dickerson TMK, Palmiter RD (2009) Dopamine is necessary for cue-dependent fear conditioning. J Neurosci 29:11089-11097. CrossRef Medline

Fiorillo CD (2013) Two dimensions of value: dopamine neurons represent reward but not aversiveness. Science 341:546-549. CrossRef Medline

Fiorillo CD, Yun SR, Song MR (2013) Diversity and homogeneity in responses of midbrain dopamine neurons. J Neurosci 33:4693-4709. CrossRef Medline

Gerfen CR (1992) The neostriatal mosaic: multiple levels of compartmental organization in the basal ganglia. Annu Rev Neurosci 15:285-320. CrossRef Medline

Guarraci FA, Kapp BS (1999) An electrophysiological characterization of ventral tegmental area dopaminergic neurons during differential pavlov- 
ian fear conditioning in the awake rabbit. Behav Brain Res 99:169-179. CrossRef Medline

Guimaraes AR, Melcher JR, Talavage TM, Baker JR, Ledden P, Rosen BR, Kiang NYS, Fullerton BC, Weisskoff RM (1998) Imaging subcortical auditory activity in humans. Hum Brain Mapp 6:33-41. CrossRef Medline

Guitart-Masip M, Fuentemilla L, Bach DR, Huys QJM, Dayan P, Dolan RJ, Duzel E (2011) Action dominates valence in anticipatory representations in the human striatum and dopaminergic midbrain. J Neurosci 31:7867-7875. CrossRef Medline

Haber SN, Fudge JL, McFarland NR (2000) Striatonigrostriatal pathways in primates form an ascending spiral from the shell to the dorsolateral striatum. J Neurosci 20:2369-2382. Medline

Hikida T, Kimura K, Wada N, Funabiki K, Nakanishi S (2010) Distinct roles of synaptic transmission in direct and indirect striatal pathways to reward and aversive behavior. Neuron 66:896-907. CrossRef Medline

Hikosaka O (2010) The habenula: from stress evasion to value-based decision-making. Nat Rev Neurosci 11:503-513. CrossRef Medline

Hong S, Jhou TC, Smith M, Saleem KS, Hikosaka O (2011) Negative reward signals from the lateral habenula to dopamine neurons are mediated by rostromedial tegmental nucleus in primates. J Neurosci 31:11457-11471. CrossRef Medline

Jensen J, McIntosh AR, Crawley AP, Mikulis DJ, Remington G, Kapur S (2003) Direct activation of the ventral striatum in anticipation of aversive stimuli. Neuron 40:1251-1257. CrossRef Medline

Jensen J, Smith AJ, Willeit M, Crawley AP, Mikulis DJ, Vitcu I, Kapur S (2007) Separate brain regions code for salience vs. valence during reward prediction in humans. Hum Brain Mapp 28:294-302. CrossRef Medline

Jhou TC, Fields HL, Baxter MG, Saper CB, Holland PC (2009) The rostromedial tegmental nucleus (RMTg), a GABAergic afferent to midbrain dopamine neurons, encodes aversive stimuli and inhibits motor responses. Neuron 61:786-800. CrossRef Medline

Ji H, Shepard PD (2007) Lateral habenula stimulation inhibits rat midbrain dopamine neurons through a GABAA receptor-mediated mechanism. J Neurosci 27:6923-6930. CrossRef Medline

Klein JT, Platt ML (2013) Social information signaling by neurons in primate striatum. Curr Biol 23:691-696. CrossRef Medline

Kravitz AV, Tye LD, Kreitzer AC (2012) Distinct roles for direct and indirect pathway striatal neurons in reinforcement. Nat Neurosci 15:816-818. CrossRef Medline

Krebs RM, Heipertz D, Schuetze H, Duzel E (2011) Novelty increases the mesolimbic functional connectivity of the substantia nigra/ventral tegmental area (SN/VTA) during reward anticipation: evidence from highresolution fMRI. Neuroimage 58:647-655. CrossRef Medline

Lammel S, Ion DI, Roeper J, Malenka RC (2011) Projection-specific modulation of dopamine neuron synapses by aversive and rewarding stimuli. Neuron 70:855-862. CrossRef Medline

Lammel S, Lim BK, Ran C, Huang KW, Betley MJ, Tye KM, Deisseroth K, Malenka RC (2012) Input-specific control of reward and aversion in the ventral tegmental area. Nature 491:212-217. CrossRef Medline

Lawson RP, Drevets WC, Roiser JP (2013) Defining the habenula in human neuroimaging studies. Neuroimage 64:722-727. CrossRef Medline

Lewis DA, Sesack SR (1997) Chapter VI dopamine systems in the primate brain. Handb Chem Neuroanat 13:263-375. CrossRef

Mantz J, Thierry AM, Glowinski J (1989) Effect of noxious tail pinch on the discharge rate of mesocortical and mesolimbic dopamine neurons: selective activation of the mesocortical system. Brain Res 476:377-381. CrossRef Medline

Matsumoto M, Hikosaka O (2007) Lateral habenula as a source of negative reward signals in dopamine neurons. Nature 447:1111-1115. CrossRef Medline

Matsumoto M, Hikosaka O (2009) Representation of negative motivational value in the primate lateral habenula. Nat Neurosci 12:77-84. CrossRef Medline

Matsumoto M, Hikosaka O (2009) Two types of dopamine neuron distinctly convey positive and negative motivational signals. Nature 459: 837-841. CrossRef Medline

McClure SM, Berns GS, Montague PR (2003) Temporal prediction errors in a passive learning task activate human striatum. Neuron 38:339-346. CrossRef Medline

McClure SM, Ericson KM, Laibson DI, Loewenstein G, Cohen JD (2007) Time discounting for primary rewards. J Neurosci 27:5796-5804. CrossRef Medline
Menon M, Jensen J, Vitcu I, Graff-Guerrero A, Crawley A, Smith MA, Kapur S (2007) Temporal difference modeling of the blood-oxygen level dependent response during aversive conditioning in humans: effects of dopaminergic modulation. Biol Psychiatry 62:765-772. CrossRef Medline

Naidich TP, Haacke EM, Kollias SS, Sorensen AG, Duvernoy HM, Delman BN (2009) Duvernoy's atlas of the human brain stem and cerebellum. Vienna: Springer.

Napadow V, Dhond R, Kennedy D, Hui KKS, Makris N (2006) Automated brainstem co-registration (ABC) for MRI. NeuroImage 32:1113-1119. CrossRef Medline

Nichols TE, Holmes AP (2002) Nonparametric permutation tests for functional neuroimaging: a primer with examples. Hum Brain Mapp 15:1-25. CrossRef Medline

O’Doherty JP, Buchanan TW, Seymour B, Dolan RJ (2006) Predictive neural coding of reward preference involves dissociable responses in human ventral midbrain and ventral striatum. Neuron 49:157-166. CrossRef Medline

Peyron R, Laurent B, García-Larrea L (2000) Functional imaging of brain responses to pain. A review and meta-analysis. Neurophysiol Clin 30:263288. CrossRef Medline

Pezze MA, Feldon J (2004) Mesolimbic dopaminergic pathways in fear conditioning. Prog Neurobiol 74:301-320. CrossRef Medline

Ploghaus A, Tracey I, Gati JS, Clare S, Menon RS, Matthews PM, Rawlins JN (1999) Dissociating pain from its anticipation in the human brain. Science 284:1979-1981. CrossRef Medline

Porcelli AJ, Lewis AH, Delgado MR (2012) Acute stress influences neural circuits of reward processing. Front Neurosci 6:157. CrossRef Medline

Ranft K, Dobrowolny H, Krell D, Bielau H, Bogerts B, Bernstein HG (2010) Evidence for structural abnormalities of the human habenular complex in affective disorders but not in schizophrenia. Psychol Med 40:557-567. CrossRef Medline

Redish AD (2004) Addiction as a computational process gone awry. Science 306:1944-1947. CrossRef Medline

Rissman J, Gazzaley A, D’Esposito M (2004) Measuring functional connectivity during distinct stages of a cognitive task. Neuroimage 23:752-763. CrossRef Medline

Savitz JB, Bonne O, Nugent AC, Vythilingam M, Bogers W, Charney DS, Drevets WC (2011) Habenula volume in post-traumatic stress disorder measured with high-resolution MRI. Biol Mood Anxiety Disord 1:7. CrossRef Medline

Schultz W (2013) Updating dopamine reward signals. Curr Opin Neurobiol 23:229-238. CrossRef Medline

Schultz W, Dayan P, Montague PR (1997) A neural substrate of prediction and reward. Science 275:1593-1599. CrossRef Medline

Seymour B, O'Doherty JP, Koltzenburg M, Wiech K, Frackowiak R, Friston K, Dolan R (2005) Opponent appetitive-aversive neural processes underlie predictive learning of pain relief. Nat Neurosci 8:1234-1240. CrossRef Medline

Seymour B, Daw N, Dayan P, Singer T, Dolan R (2007) Differential encoding of losses and gains in the human striatum. J Neurosci 27:4826-4831. CrossRef Medline

Shelton L, Pendse G, Maleki N, Moulton EA, Lebel A, Becerra L, Borsook D (2012) Mapping pain activation and connectivity of the human habenula. J Neurophysiol 107:2633-2648. CrossRef Medline

Smith Y, Kieval JZ (2000) Anatomy of the dopamine system in the basal ganglia. Trends Neurosci 23:S28-S33. CrossRef Medline

Smith Y, Lavoie B, Dumas J, Parent A (1989) Evidence for a distinct nigropallidal dopaminergic projection in the squirrel monkey. Brain Res 482: 381-386. CrossRef Medline

Stamatakis AM, Stuber GD (2012) Activation of lateral habenula inputs to the ventral midbrain promotes behavioral avoidance. Nat Neurosci 15: 1105-1107. CrossRef Medline

Talairach J, Tournoux P (1988) Co-planar stereotaxic atlas of the human brain. 3-Dimensional proportional system: an approach to cerebral imaging. Stuttgart, Germany: Thieme.

Thierry AM, Tassin JP, Blanc G, Glowinski J (1976) Selective activation of the mesocortical DA system by stress. Nature 263:242-244. CrossRef Medline

Thornton EW, Bradbury GE (1989) Effort and stress influence the effect of lesion of the habenula complex in one-way active avoidance learning. Physiol Behav 45:929-935. CrossRef Medline

Tom SM, Fox CR, Trepel C, Poldrack RA (2007) The neural basis of loss 
aversion in decision-making under risk. Science 315:515-518. CrossRef Medline

Treadway MT, Buckholtz JW, Zald DH (2013) Perceived stress predicts altered reward and loss feedback processing in medial prefrontal cortex. Front Hum Neurosci 7:180. CrossRef Medline

Vlaev I, Seymour B, Dolan RJ, Chater N (2009) The price of pain and the value of suffering. Psychol Sci 20:309-317. CrossRef Medline

Wise SP (2008) Forward frontal fields: phylogeny and fundamental function. Trends Neurosci 31:599-608. CrossRef Medline

Wittmann BC, Schott BH, Guderian S, Frey JU, Heinze HJ, Düzel E (2005) Reward-related fMRI activation of dopaminergic midbrain is associated with enhanced hippocampus-dependent long-term memory formation. Neuron 45:459-467. CrossRef Medline

Yacubian J, Gläscher J, Schroeder K, Sommer T, Braus DF, Büchel C (2006) Dissociable systems for gain- and loss-related value predictions and errors of prediction in the human brain. J Neurosci 26:95309537. CrossRef Medline
Yushkevich PA, Piven J, Hazlett HC, Smith RG, Ho S, Gee JC, Gerig G (2006) User-guided 3D active contour segmentation of anatomical structures: significantly improved efficiency and reliability. Neuroimage 31:11161128. CrossRef Medline

Zhang WT, Mainero C, Kumar A, Wiggins CJ, Benner T, Purdon PL, Bolar DS, Kwong KK, Sorensen AG (2006) Strategies for improving the detection of fMRI activation in trigeminal pathways with cardiac gating. Neuroimage 31:1506-1512. CrossRef Medline

Zweifel LS, Parker JG, Lobb CJ, Rainwater A, Wall VZ, Fadok JP, Darvas M, Kim MJ, Mizumori SJ, Paladini CA, Phillips PE, Palmiter RD (2009) Disruption of NMDAR-dependent burst firing by dopamine neurons provides selective assessment of phasic dopamine-dependent behavior. Proc Natl Acad Sci U S A 106:7281-7288. CrossRef Medline

Zweifel LS, Fadok JP, Argilli E, Garelick MG, Jones GL, Dickerson TMK, Allen JM, Mizumori SJY, Bonci A, Palmiter RD (2011) Activation of dopamine neurons is critical for aversive conditioning and prevention of generalized anxiety. Nat Neurosci 14:620-626. CrossRef Medline 